\title{
Formação de professores da educação básica: um estudo de caso do Parfor
}

\author{
Basic education teacher training: a case study of Parfor \\ Formación de docentes de educación básica: un estudio de caso de Parfor
}

SOFIA DE BRITO FERREIRA https://orcid.org/0000-0002-8552-4537 Instituto Brasileiro de Educação, Desenvolvimento e Pesquisa - IDP

Faculdade de Administração Pública Brasília, DF, Brasil

CAIO CORDEIRO DE RESENDE http://orcid.org/0000-0003-4732-5788

Instituto Brasileiro de Educação, Desenvolvimento e Pesquisa - IDP

Faculdade de Economia

Núcleo de Administração Pública

Brasília, DF, Brasil

\begin{abstract}
Resumo: Este artigo apresenta e analisa os resultados de uma pesquisa qualitativa de avaliação do Programa Nacional de Formação de Professores da Educação Básica (Parfor). O programa tem como objetivo fomentar a oferta de educação superior gratuita a professores da educação básica. Neste trabalho, realizamos ampla pesquisa junto a egressos do programa com os objetivos de compreender o perfil dos professores beneficiados, elucidar as principais dificuldades para frequentar as aulas do Parfor e realizar uma avaliação do programa sob a ótica de seus beneficiários. Participaram da pesquisa 1.225 professores. Os resultados apontam para a necessidade de melhora do processo seletivo para o Parfor, tendo em vista o grande número de professores que atualmente frequentam cursos fora de sua área de atuação. Além disso, mostra-se como o baixo envolvimento das secretarias de educação tem causado dificuldades aos professores beneficiados pelo programa.
\end{abstract}

Palavras-chave: Avaliação de Políticas Públicas; Formação de Professores; Educação Básica; Parfor.

Abstract: This paper presents and analyzes the results of a qualitative research of the National Basic Education Teacher Training Program (Parfor). The program aims to provide free higher education to teachers of basic education. In this work, we conducted an extensive research with graduates of the program to understand the profile of the teachers benefited by the program, to clarify the main difficulties to attend Parfor classes, and to carry out an evaluation of the program from the perspective of its beneficiaries. 1,225 teachers participated in the research. The results show the need to improve the selection process for Parfor, given the large number of teachers who currently attend courses outside their area of expertise. Also, it shows bow the low involvement of state education departments has caused difficulties for participating teachers.

Keywords: Public Policy Evaluation; Teacher training; Basic Education; Parfor. 
Resumen: Este articulo presenta y analiza los resultados de una investigación cualitativa del Programa Nacional de Formación de Docentes de Educación Básica (Parfor). El programa tiene como objetivo proporcionar educación superior gratuita a los profesores de educación básica. En este trabajo, realizamos una extensa investigación con egresados del programa para comprender el perfil de los docentes beneficiados, esclarecer las principales dificultades para asistir a las clases de Parfor y realizar una evaluación del programa desde la perspectiva de sus beneficiarios. Participaron en la investigación 1.225 profesores. Los resultados apuntan la necesidad de mejorar el proceso de selección de Parfor, dada la gran cantidad de profesores que actualmente asisten a cursos fuera de su área de docencia. Además, muestra cómo la escasa participación de los departamentos de educación estatales ha provocado dificultades para los docentes beneficiados por el programa.

Palabras clave: Evaluación de Politicas Públicas; Formación de profesores; Educación Básica; Parfor.

\section{INTRODUÇÃO}

Conforme o Censo da Educação Básica de 2018, 4 (quatro) em cada 10 (dez) professores do Ensino Fundamental da rede pública não possuem formação de ensino superior na área em que atuam. Desses, cerca 15\% não possuem nenhum tipo de formação em nível superior.

Não é sem razão, portanto, que, ao longo dos últimos anos, foram lançadas diversas políticas públicas em nível municipal, estadual e federal com vistas a fomentar a capacitação em nível superior dos docentes da educação básica no País. Um dos exemplos mais relevantes foi a Política Nacional de Formação de Profissionais da Educação Básica, instituída pelo governo federal, no início de 2009, com a finalidade de estimular a formação inicial e continuada dos professores da rede pública de educação básica (BRASIL, 2009). Em maio do mesmo ano, foi lançado aquele que viria a ser um dos principais instrumentos dessa Política: o Programa Nacional de Formação de Professores da Educação Básica (Parfor).

Sob responsabilidade da Coordenação de Aperfeiçoamento de Pessoal de Nível Superior (CAPES), o Parfor tem como objetivo principal fomentar a oferta de educação superior, gratuita e de qualidade para professores da rede pública de educação básica que não possuem a formação específica em sua área de atuação (CAPES, 2014). Para isso, o programa, em conjunto com Instituições de Ensino Superior (IES) parceiras, oferta turmas de ensino superior gratuitas em cursos de Primeira e Segunda Licenciaturas e de Formação Pedagógica.

Neste trabalho, realizamos uma ampla pesquisa junto a egressos formados e desistentes - do Parfor com os objetivos principais de : i) compreender o perfil dos professores beneficiados pelo programa; ii) elucidar as principais 
dificuldades enfrentadas pelos beneficiários para frequentar as aulas do Parfor e as principais razões para a desistência; e iii) realizar uma avaliação do programa sob a ótica de seus beneficiários.

O Programa já contemplou cerca de 87 mil professores (considerando atuais beneficiários e egressos) ${ }^{1}$. Desses, 67 mil já haviam concluído (43 mil) ou abandonado (24 mil) o programa até o final de 2018. Enviamos nossos questionários a todos esses egressos. Do total de professores contatados, 1.225 responderam à pesquisa.

Sintetizamos os principais resultados dos questionários aplicados em 5 grandes "lições" sobre o Parfor, que resumimos a seguir: i) é necessário aprimorar os critérios de seleção do programa, já que cerca de 30\% das bolsas foram destinadas para o financiamento de cursos fora da área de atuação dos professores; ii) há grande participação de professores com contrato temporário com a rede pública, o que levanta dúvidas sobre os potenciais retornos desse investimento na forma de aumento de qualidade da educação; iii) os principais desafios dos professores-discentes para participação e conclusão dos cursos no Parfor estão relacionados à conciliação das tarefas docentes com a carga de estudos e a dificuldades de transporte; iv) as secretarias de educação não têm atuado ativamente no acompanhamento do desempenho acadêmico de professores de sua rede nem na garantia de liberação nos dias e horários do curso; e v) academicamente, o programa tem agradado aos professores, embora existam espaços para melhoria, principalmente no que tange à aplicabilidade do conteúdo ofertado no dia a dia de um professor da educação básica.

O restante deste artigo está organizado em 6 seções. Nas duas seções seguintes, apresentamos um breve histórico das políticas de formação de professores no Brasil a partir da Constituição Federal de 1988 e descrevemos em detalhes o Parfor. Na seção 4, realizamos uma breve revisão da literatura sobre pesquisas relacionadas ao programa, seus principais resultados e conclusões. A seção 5 apresenta os procedimentos metodológicos da pesquisa e a seção 6 , os principais resultados. A seção 7 conclui o trabalho.

\footnotetext{
1 Dados retirados, em dezembro de 2018, da Plataforma Freire, sistema eletrônico da CAPES que gerencia as turmas e realiza o acompanhamento do Programa.
} 


\section{BREVE HISTÓRICO DAS POLÍTICAS PÚBLICAS FEDERAIS PARA FORMAÇÃO DE PROFESSORES}

Conforme destaca Mazzeu (2009), a década de 1990 foi caracterizada pela intensificação de políticas públicas de formação de professores apoiadas nas demandas de "reestruturação produtiva para a formação ou qualificação do trabalhador". Segundo o autor, tratou-se de um período de reformas na educação brasileira "marcada pela produção de documentos oficiais, leis, diretrizes e decretos embasados pelas recomendações de organismos multilaterais internacionais e regionais, dentre os quais destacamos: Banco Mundial, UNESCO, UNICEF, CEPAL e PNUD” (MAZZEU, 2009).

O Plano Decenal de Educação para Todos (1993-2003) é um dos exemplos mais simbólicos dessa tentativa de alinhar as políticas públicas de formação de professores com as orientações dos organismos multilaterais, citados pelo autor. De acordo com Shiroma, Moraes e Evangelista (2004 apud MAZZEU, 2009), "com esse plano, o Brasil traçava as metas locais a partir do acordo firmado em Jomtien $^{2}$ e acenava aos organismos multilaterais que o projeto educacional por eles prescrito seria aqui implementado".

Um segundo marco desse processo foi a promulgação da Lei de Diretrizes e Bases da Educação Nacional, que, pela primeira vez, previu a obrigatoriedade da formação em nível superior para professores da educação básica (BRASIL, 1996) ${ }^{3}$. A primeira versão do Plano Nacional de Educação (PNE), promulgado em 2001, reforçou essa obrigação ao trazer, como um dos objetivos e metas para o magistério da educação básica para os 10 anos seguintes, que $70 \%$ dos professores de educação infantil e de ensino fundamental e 100\% dos professores de ensino médio possuíssem formação específica de nível superior de licenciatura plena em instituições qualificadas (BRASIL, 2001).

O PNE deixava claro a responsabilidade da União e, especificamente, das universidades públicas nesse processo ([às universidades públicas] cabe qualificar os docentes que atuam na educação básica), assim como elencava diversos instrumentos para o alcance dessas metas -como, por exemplo, generalizar, nas instituicõos de ensino superior públicas, cursos regulares noturnos e cursos modulares de licenciatura plena que facilitem o acesso dos docentes em exercício à formação nesse nivvel de ensino (BRASIL, 2001). Esses instrumentos foram definidos nos Objetivos e Metas para o Magistério da Educação Básica nos 15 a 19.

\footnotetext{
2 Declaração Mundial sobre Educação para Todos, firmada em 1990 durante a Conferência Mundial sobre Educação, realizada em Jomtien, na Tailândia.

3 O art. 62 da LDB admite como formação mínima para o exercício do magistério na educação infantil e nas quatro primeiras séries do ensino fundamental, a oferecida em nível médio, na modalidade normal.
} 
Em 2009, foi instituída a Política Nacional de Formação de Profissionais do Magistério da Educação Básica, "com a finalidade de organizar, em regime de colaboração entre a União, os Estados, o Distrito Federal e os Municípios, a formação inicial e continuada dos profissionais do magistério para as redes públicas de educação básica" (BRASIL, 2009). Previu-se, ainda, a responsabilidade da CAPES no fomento a programas de formação inicial e continuada de professores da educação básica.

A Política Nacional se tornaria o principal instrumento da União para atingir os objetivos de formação de professores do PNE. Uma das principais finalidades dessa nova política era, justamente, atender aos já mencionados Objetivos e Metas nos15 a 19 do Magistério da Educação Básica no PNE vigente à época (decênio 2001 a 2010). Essas metas, como vimos, previam que o poder público incentivasse as universidades e as demais instituições públicas de ensino superior a oferecer cursos de formação de professores e de pessoal para as diferentes áreas da educação. É importante destacar que a política foca na formação de professores já em exercício, passando ao largo do importante debate acerca da formação inicial de professores (GATTI, 2014).

Em 2014, foi aprovada nova versão do PNE (BRASIL, 2014). Esta nova versão também trazia, entre as suas 20 metas, duas especificamente voltadas à formação de professores: a Meta 15 (que prevê que todos os professores da educação básica tenham formação específica de nível superior, obtida em curso de licenciatura na área do conhecimento em que atuam) e a Meta 16 (que prevê formar, em nível de pós-graduação, 50\% dos professores da educação básica). Esta nova versão do PNE previa, ainda, o lançamento de uma nova política nacional de formação dos profissionais da educação. Essa previsão foi materializada no Decreto $\mathrm{n}^{\circ}$ 8.752, de 9 de maio de 2016, que dispõe sobre a Política Nacional de Formação dos Professores da Educação Básica (BRASIL, 2016).

Dados do Censo da Educação Básica mostram que, de 2011 a 2018, o percentual de docentes da rede pública de Ensino Fundamental sem formação em nível superior caiu de 24\% para 14\% (Tabela 1). As regiões Norte e Nordeste do País concentram o maior percentual de professores sem formação - 23\% e 25\%, respectivamente. As regiões Centro-Oeste, Sul e Sudeste apresentam níveis bem inferiores, mas ainda bastante significativos - 8\%,7\% e 7\%, respectivamente. 


\section{Tabela 1 - Professores da rede pública de Ensino Fundamental sem formação de nível superior (2011-2018)}

\begin{tabular}{llll}
\hline \hline & $\mathbf{2 0 1 1}$ & $\mathbf{2 0 1 4}$ & $\mathbf{2 0 1 8}$ \\
\hline Centro-Oeste & $88 \%$ & $91 \%$ & $92 \%$ \\
Nordeste & $58 \%$ & $68 \%$ & $75 \%$ \\
Norte & $60 \%$ & $70 \%$ & $77 \%$ \\
Sudeste & $88 \%$ & $90 \%$ & $93 \%$ \\
Sul & $86 \%$ & $89 \%$ & $93 \%$ \\
\hline Brasil & $\mathbf{7 6 \%}$ & $\mathbf{8 2 \%}$ & $\mathbf{8 6 \%}$ \\
\hline
\end{tabular}

Fonte: Censo da Educação Básica - INEP (2011, 2014, 2018). Elaboração própria.

Esses dados, contudo, levam em consideração qualquer tipo de formação (licenciatura, bacharelado e tecnológico em qualquer área de atuação). Além disso, os docentes podem possuir formação superior em licenciatura, mas atuarem fora da área de conhecimento da graduação. Portanto, o percentual de profissionais docentes sem a formação prevista pela Meta 15 do PNE é maior do que o representado na Tabela acima (uma vez que a meta prevê que todos os professores possuam formação específica de nível superior, obtida em licenciatura na área de conbecimento em que atuam).

A Tabela 2 classifica os professores conforme o tipo de formação. No Grupo 1, estão os docentes com formação superior de licenciatura (ou bacharelado com complementação pedagógica) na mesma área da disciplina em que leciona; no Grupo 2, docentes com bacharelado (sem complementação pedagógica) na mesma área da disciplina; nos Grupo 3 e 4, docentes com formação em licenciatura (ou bacharelado com complementação) e bacharelado (sem complementação) em área diferente daquela que leciona; e, no Grupo 5, docentes sem formação superior ${ }^{4}$.

4 As pequenas diferenças observadas entre as Tabelas 1 e 2 ocorrem em virtude da metodologia adotada pelo Inep para o cálculo de cada indicador. No cálculo da Tabela 2, por exemplo, é considerado não simplesmente o número de professores, mas a situação do professor em cada disciplina e turma em que atua. Para mais informações, vide Inep (2014). 


\section{Tabela 2 - Tipo de formação dos professores da rede pública de Ensino Fundamental (2018)}

\begin{tabular}{lccccc}
\hline & Grupo 1 & Grupo 2 & Grupo 3 & Grupo 4 & Grupo 5 \\
\hline Centro-Oeste & $65 \%$ & $5 \%$ & $18 \%$ & $3 \%$ & $9 \%$ \\
Nordeste & $42 \%$ & $1 \%$ & $27 \%$ & $5 \%$ & $25 \%$ \\
Norte & $50 \%$ & $0 \%$ & $22 \%$ & $3 \%$ & $24 \%$ \\
Sudeste & $72 \%$ & $1 \%$ & $16 \%$ & $4 \%$ & $8 \%$ \\
Sul & $71 \%$ & $1 \%$ & $18 \%$ & $3 \%$ & $8 \%$ \\
\hline Brasil & $\mathbf{5 9 \%}$ & $\mathbf{1 \%}$ & $\mathbf{2 1 \%}$ & $\mathbf{4 \%}$ & $\mathbf{1 5 \%}$ \\
\hline
\end{tabular}

Fonte: Censo da Educação Básica - INEP (2018). Elaboração própria.

Segundo Gatti (2014), a "improvisação” de professores em várias áreas do conhecimento é um dos maiores problemas que se observa no tocante a formação de professores para a educação básica no País. A afirmação da autora é corroborada pelos dados da Tabela 2. Como se nota, quando analisamos não somente a formação em nível superior, mas a formação em licenciatura na área em que o professor atua, fica evidente que parte significativa dos professores que atuam na rede pública de Ensino Fundamental não possui formação na disciplina que lecionam. No Nordeste, por exemplo, menos de $50 \%$ dos professores possuem formação em nível superior em sua respectiva área de atuação. Mesmo em regiões mais desenvolvidas, como o Sul e o Sudeste, quase 30\% dos professores não atendiam a esse requisito.

Fica evidente, assim, a necessidade de políticas dirigidas especificamente para qualificar a formação inicial de professores, de forma a garantir que cada vez mais professores pertençam ao Grupo 1 da Tabela 2, ou seja, que tenham formação superior de licenciatura (ou bacharelado com complementação pedagógica) na mesma área da disciplina em que lecionam. Como veremos na seguinte, esse é o principal objetivo do Parfor

\section{O PROGRAMA NACIONAL DE FORMAÇÃO DE PROFESSORES DA EDUCAÇÃO BÁSICA}

O Parfor foi lançado, em 28 de maio de 2009, como um dos principais instrumentos de implementação da Política Nacional de Formação de Professores. O programa tem como objetivo principal induzir e fomentar a oferta de educação superior, gratuita e de qualidade para docentes da rede pública de educação básica, 
contribuindo, assim, para o alcance da Meta 15 do PNE (CAPES, 2014). Para isso, o programa oferta cursos de Primeira e Segunda Licenciaturas e de Formação Pedagógica

Para formalizar o Programa, o Ministério da Educação (MEC), por meio da CAPES, e os Estados, por meio de suas Secretarias Estaduais de Educação, firmaram um Acordo de Cooperação Técnica (ACT), com vigência de sete anos. Os municípios também pactuaram com o ACT, no momento de adesão ao Plano de Metas Compromisso Todos pela Educação. Inicialmente, apenas as IES federais e estaduais ofertaram cursos no âmbito do programa. Em 2013, foram também convidadas para o programa IES privadas sem fins lucrativos. A participação no programa é formalizada por meio de Termo de Adesão, que descreve os compromissos da IES no âmbito do Parfor.

O compromisso firmado entre a CAPES e as IES visa ao custeio de turmas especiais, classificadas como aquelas com calendário específico de funcionamento e voltadas apenas para os beneficiários do Programa. A CAPES repassa às IES, a título de despesas de custeio, valores que variam de 15 a 20 mil reais por semestre, a depender do local de funcionamento da turma (dentro ou fora dos campi das IES) $)^{5}$.

Além do custeio, a CAPES transfere diretamente aos professores formadores que ministram aulas ou desempenham atividades de coordenação no âmbito do Parfor bolsas de estudo que variam de R \$ 1.100,00 (Professor Formador II) a R $\$ 1.500,00$ (Coordenador Geral). Não há qualquer tipo de auxílio financeiro, financiado pelo Governo Federal, aos professores discentes do Programa.

Conforme dados da Diretoria de Educação Básica da CAPES, entre 2009 e 2017, o Governo Federal investiu no Parfor cerca de R\$1,1 bilhão. Desse total, aproximadamente $73 \%$ foram destinados ao pagamento de bolsas e o restante às despesas de custeio. Esses recursos financiaram cerca de 2.900 turmas, em pouco mais de 100 instituições parceiras. Foram contemplados com turmas do programa aproximadamente 500 municípios. Essas turmas, contudo, contaram com a participação de professores oriundos de mais de 3.000 municípios brasileiros.

A Tabela 3 apresenta a distribuição regional das turmas do Parfor. Cerca de $86 \%$ das turmas concentraram-se nas regiões Norte e Nordeste do País. Tratase de algo esperado, uma vez que, conforme vimos nas Tabelas 1 e 2, essas são as regiões com o maior percentual de professores sem formação superior em sua área de atuação. Nesse sentido, a focalização geográfica do programa vem se mostrando acertada.

5 O cálculo do valor a ser repassado é feito de acordo com o art. 34 da Portaria no 82, de 17 de abril de 2017 (BRASIL, 2017a), alterada pela Portaria n 159, de 15 de agosto de 2017 (BRASIL, 2017b).

424 - Rev. Bras. Polít. Adm. Educ. - v. 37, n. 1, p. 417 - 446, jan./abr. 2021 
Tabela 3 - Quantidade de IES e Turmas por Região (2009 e 2018)

\begin{tabular}{|c|c|c|c|}
\hline Região & Número de IES & Número de Turmas & $\begin{array}{c}\text { Percentual de Turmas por } \\
\text { Região }\end{array}$ \\
\hline Norte & 18 & 1.306 & $45 \%$ \\
\hline Nordeste & 28 & 1.177 & $41 \%$ \\
\hline Centro-Oeste & 5 & 63 & $2 \%$ \\
\hline Sudeste & 26 & 103 & $3 \%$ \\
\hline Sul & 27 & 253 & $9 \%$ \\
\hline Total & 104 & 2902 & $100 \%$ \\
\hline
\end{tabular}

Fonte: Plataforma Freire/CAPES/MEC, dezembro 2018. Elaboração própria.

A Tabela 4, por sua vez, traz o histórico de participantes do programa entre 2009 e 2018. Como se nota, nos seus quase 10 anos de vigência, foram beneficiados pelo programa cerca de 87,5 mil professores da rede pública de educação. Desses, 43,5 mil (49,7\%) completaram sua formação no âmbito do programa e 18,5 mil (21,1\%) encontram-se atualmente frequentando aulas no âmbito do programa.

Tabela 4 - Participantes do Parfor (2009 e 2018)

\begin{tabular}{lc}
\hline \hline Status & Total de Estudantes \\
\hline Formados & 43.549 \\
Cursando & 18.455 \\
Desvinculados & 24.226 \\
Trancados/Transferidos & 1.140 \\
Falecidos & 118 \\
\hline Total & 87.488
\end{tabular}

Fonte: Plataforma Freire/CAPES/MEC, dezembro 2018. Elaboração própria.

Chama a atenção o grande número de desvinculados do Parfor - 24 mil professores ou $36 \%$ do total de egressos do programa. O status de "desvinculado" abrange todos os professores que, por algum motivo, desistiram de concluir o curso. Não há informações nos registros administrativos do programa sobre as razões que levaram esses professores a desistir. Tampouco conhecemos pesquisas acadêmicas que buscaram esclarecer os motivos pelos quais 1 de cada 3 professores que se matriculam no Parfor acabam abandonando o curso antes de concluir sua graduação. Um dos objetivos desta pesquisa foi, justamente, 
compreender as principais razões para esses altos índices de desistência. Antes, contudo, faremos uma breve revisão de trabalhos que, tal como este, buscaram avaliar a implementação do Parfor.

\section{REVISÃO DA LITERATURA}

Como vimos na seção 2, nos últimos 30 anos, foram várias as leis, as políticas e os programas destinados a fomentar a formação de professores da educação básica. Em paralelo, cresceu, igualmente, o número de pesquisas sobre formação de professores (ANDRE, 2009), bem como a percepção da importância da formação inicial e continuada de professores como um dos principais elementos de valorização da docência (GATTI; BARRETO, 2009; GATTI, BARRETO; ANDRE, 2011). Nesta seção, focaremos em trabalhos que buscaram analisar especificamente o Parfor, particularmente naqueles que elucidam aspectos relevantes sob o ponto de vista da implementação do programa.

Uma das principais dificuldades para participação dos professoresdiscentes no Parfor apontadas pela literatura diz respeito à necessidade de conciliar as tarefas como professor da educação básica e como estudante do Parfor. O acúmulo das funções torna necessário ao docente abdicar de horas de descanso e de convivência familiar para frequentarem as aulas do programa, seja nos finais de semana seja durante as férias (JARA, 2014; SOTERO, 2016). Além disso, diversos docentes encontraram dificuldades como a falta de liberação das secretarias ou da direção da escola para frequentar as aulas do Programa (MARQUES, 2016).

A questão da liberação dos professores levou, ainda, a outros problemas. Como aponta Marques (2016) em pesquisa com professores da rede estadual de educação do Amazonas, houve falhas na divulgação e na orientação dos docentes sobre os processos de inscrição no programa. Segundo a autora, de um lado, as secretarias de educação solicitavam a liberação dos professores para que estes frequentassem as aulas do Parfor sem disponibilizar professor substituto para atuar na vaga do professor liberado; de outro lado, as escolas, por saberem que não contariam com professores substitutos, deixavam de divulgar o Programa.

A crítica à atuação das secretarias de educação não se limitou a problemas na divulgação. Diversos autores criticaram a falta de apoio das secretarias aos professores-discentes, tendo muitas delas limitado sua atuação ao processo de validação das inscrições, transferindo o restante do ônus para as IES (PAIVA, 2018; OLIVEIRA, 2015).

Outros problemas comumente apontados pela literatura estão relacionados a questões de natureza logística, como, por exemplo, os custos e as dificuldades de acesso ao local das aulas, principalmente quando as turmas eram 
localizadas em outros municípios. Em pesquisa focada nas turmas do Parfor na cidade de Codó, no Maranhão, Paiva (2018) mostrou como há alta concentração de professores atuantes em escolas rurais (65\%), tendo boa parte deles dificuldade em se deslocar semanalmente para frequentar as aulas do curso.

Outra questão relevante é a participação de professores com contrato temporário. Por um lado, conforme destaca Marques (2016), a participação desses professores é justificada pelo fato de que, principalmente nos pequenos municípios, o corpo docente é formado prioritariamente por professores que entraram no serviço público mediante processo seletivo simplificado. Por outro lado, segundo a autora, a participação dos professores temporários no Programa deveria ser repensada, "visto que os mesmos não permanecem nos cursos em que foram matriculados, por falta de condições financeiras para cobrir despesas com o seu deslocamento e estadia" (MARQUES, 2016).

Identificaram-se, ainda, na literatura, outras críticas ao Parfor: falta de interlocução entre União, Estados e Municípios (AVANCINI, 2011; D’AVILA, 2014); qualidade da formação ofertada (SOTERO, 2016); concentração em cursos de nível superior (JARA, 2014; SOTERO, 2016); adequação do currículo à realidade dos professores (SILVA JÚNIOR, 2010 apud GATTI, BARRETO e ANDRE, 2011); a falta de recursos didáticos e equipamentos adequados (FONSECA, 2010); altos índices de desistência (CUNHA, 2010 apud ; GATTI, BARRETO e ANDRE, 2011); e altos custos com transporte e alimentação (MARQUES, 2016).

Esses problemas de concepção e implementação do Parfor podem ser contrapostos aos pontos positivos do programa. Segundo Sotero, os professoresdiscentes apontam o Parfor como uma boa oportunidade de formação e capacitação docente, particularmente no sentido de estimular "o retorno desses sujeitos [docentes] aos estudos, pois são professoras-discentes que em sua maioria têm um tempo de trabalho significativo na Educação Básica, e que denotam certa resistência ao voltar à sala de aula como alunas" (SOTERO, 2016, p. 67). Ainda de acordo com os alunos, a formação em nível de pós-graduação stricto sensu dos professores formadores também contribui positivamente para a efetividade do Programa (PAIVA, 2018).

Do exame dos trabalhos que tiveram como metodologia entrevistas com professores discentes (MARQUES, 2016; NEIVA, 2014; SILVA JUNIOR, 2010; SOTERO, 2016), é possível perceber, ainda, a valorização do Parfor como meio de acesso à formação de nível superior em locais remotos do País. Em geral, os alunos apontaram como pontos positivos a qualidade dos professores, a infraestrutura e o apoio das Instituições de Ensino Superior - IES. 
$\mathrm{Na}$ maioria dos trabalhos analisados, a avaliação do Parfor é feita por meio de estudos de casos - locais ou regionais. Não identificamos na literatura pesquisada nenhum trabalho que buscou avaliar o programa nacionalmente, o que ressalta a importância da presente pesquisa.

\section{PROCEDIMENTOS METODOLÓGICOS}

Metodologicamente, este trabalho foi concebido como um estudo de caso e, portanto, pode ser compreendido, conforme destaca Robert Yin, como uma "investigação empírica que investiga um fenômeno contemporâneo dentro de seu contexto da vida real" (YIN, 2001, p. 32). O autor destaca, ainda, a importância de tal metodologia nas pesquisas de avaliação, destacando sua capacidade de i) descrever uma intervenção e o contexto na vida real em que ela ocorre; e ii) unir a implementação do programa com os seus efeitos.

Para realização de nosso estudo, adotaremos como principal estratégia de pesquisa as entrevistas realizadas por email com egressos do programa. Nossa base de dados é composta por todos os professores que participaram do Parfor e que, em dezembro de 2018, apresentavam o status de "formado" (43.549) e "desvinculado do curso" (24.226), o que totaliza um total de 67.581 professores (vide Tabela 4).

Inicialmente, aplicamos um piloto do questionário com uma amostra aleatória de 6.025 professores que apresentavam o status "desvinculado do curso". Essa versão preliminar do questionário foi enviada entre os dias 23/01/2019 e 31/01/2019. O teste inicial mostrou dois dos principais obstáculos a nossa pesquisa: aproximadamente $35 \%$ dos e-mails enviados retornaram, apontando e-mails cadastrados incorretamente, inexistentes ou não mais utilizados; e apenas $1 \%$ dos professores contatados nessa fase inicial responderam completamente os questionários (63 respostas).

Após o piloto, foram realizados pequenos ajustes no questionário ${ }^{6}$. Este foi, então, enviado para os demais professores "desvinculados do curso" e para o universo de professores "formados", totalizando mais de 67 mil e-mails enviados. O questionário final foi aplicado entre os dias 09/04/2019 e 17/05/2019. A participação dos professores nas duas etapas da pesquisa foi de cerca de $2 \%$,

6 As alterações realizadas no questionário dizem respeito ao ajuste de perguntas no primeiro bloco, adaptando as respostas de faixa de idade para melhor análise dos dados, e à inserção de novas questões referentes à percepção dos professores sobre a coordenação do Programa, a dificuldade de dedicação e de acompanhamento das aulas. 
totalizando 1.225 respostas completas ao questionário. Cerca de $40 \%$ dos e-mails retornaram, confirmando a baixa qualidade administrava dos dados de cadastro no Programa.

O questionário utilizado para a coleta dos dados era composto por 32 perguntas, divididas em duas seções: a primeira, composta por 17 perguntas, era focada no perfil dos professores (ex. gênero, idade, renda, estado, nível de instrução, rede de vinculação, etc.) e nas características do curso do Parfor (IES responsável, área, modalidade do curso, etc.); a segunda, composta por 15 perguntas, era focada na avaliação da experiência do professor-discente no Parfor (principais dificuldades, forma de deslocamento, desempenho da secretaria e do coordenador, avaliação acadêmica do programa, etc.). Para os desistentes do programa, havia uma pergunta adicional, que os questionava sobre as principais razões que os levaram a abandoná-lo.

Na Tabela A.1 do Apêndice, resumimos diversas características da nossa amostra, separando-a em dois grupos: desistentes (que totalizam 205 participantes) e formados (que totalizam 1.020 participantes). Como se nota, a maioria dos professores que participaram do Parfor e responderam nossa pesquisa residem nas regiões Norte-Nordeste (34\%), são mulheres (66\%), têm de 21 a 40 anos (81\%), são vinculados à rede municipal de ensino (63\%), possuem vínculo efetivo com a administração pública (68\%), atuam no Ensino Fundamental (65\%), estão há mais de 6 anos vinculados a rede pública $(62 \%)$ e possuem renda de até R\$ 2 mil (59\%). As disciplinas ministradas variam bastante, com destaque para os professores de matemática ( $9 \%$ ) e português $(7 \%)$ e para aqueles que atuam nos anos iniciais do Ensino Fundamental (29\%). Com relação ao curso frequentado no Parfor, chama a atenção a representatividade do curso de Pedagogia, responsável por 1 a cada 4 matrículas em nossa amostra. A maioria dos cursos foram ofertados durante as férias e/ou fins de semana (68\%) nos turnos matutino e vespertino (58\%). Para mais da metade dos professores (57\%), o curso foi ministrado fora de seu município de residência. Para uma parcela significativa desse grupo (35\%), as aulas ocorreram a mais de $100 \mathrm{~km}$ de seu município de residência. Finalmente, vale notar que parcela expressiva das desistências $(22 \%)$ ocorreram no período entre 2009-2011, menos de 3 anos após o início do programa.

\section{RESULTADOS}

Nesta seção, analisaremos os principais resultados do questionário aplicado. Sintetizamos esses principais resultados em 5 grandes "lições" sobre o programa. 


\section{Lição no 1: É necessário aprimorar os critérios de seleção e de validação de inscrições no programa}

Como vimos nas seções anteriores, o principal objetivo do Parfor é auxiliar no atendimento da Meta 15 do PNE (BRASIL, 2014), qual seja: que todos os professores e as professoras da educação básica possuam formação específica de nivel superior, obtida em curso de licenciatura na área de conbecimento em que atuam.

A Tabela 5 consolida a resposta a duas perguntas Q Quando você iniciou o curso do Parfor, você possuía título de graduação? e O curso que frequentou no Parfor era na sua área de atuação?). Dois pontos chamam a atenção na Tabela. Em primeiro lugar, cerca de $70 \%$ dos participantes (848 professores) já possuíam uma graduação antes de iniciar o Parfor. O Programa não foca, portanto, nos professores sem formação superior.

\section{Tabela 5 - Situação dos participantes do Parfor - graduação versus curso na área de atuação}

\begin{tabular}{|c|c|c|c|}
\hline Curso Parfor na área em que atua? & \multirow{2}{*}{ NÃO } & \multirow{2}{*}{ SIM } & \multirow{2}{*}{ TOTAL } \\
\cline { 1 - 2 } Possuía graduação? & & & 377 \\
\hline NÃO & 82 & 295 & 848 \\
\hline SIM & 282 & 566 & 1225 \\
\hline TOTAL & 364 & 861 & \\
\hline
\end{tabular}

Fonte: Elaboração própria a partir dos dados coletados

Embora 70\% dos professores que participam do Programa já tivessem formação superior, ainda é possível que o Programa contribua para o atingimento da Meta 15 do PNE (BRASIL, 2014), ao estimular que os professores titulados em outras áreas obtenham uma graduação em sua respectiva área de atuação. Esse, contudo, não é o caso para uma parcela significativa de participantes do Programa. Como mostra a Tabela 5, 282 respondentes (23\%) já tinham curso de graduação em sua respectiva área de atuação e estavam matriculados no Parfor em um curso fora de sua área de atuação; 82 respondentes (7\%) não tinham ensino superior, mas também estavam matriculados em um curso fora de sua área de atuação. Ou seja, 30\% das vagas ocupadas nos cursos no âmbito do Programa não tinham qualquer relação com o objetivo do Parfor, de garantir formação em nível superior para os profissionais da educação básica que não possuem graduação em área de atuação. Nestes casos, o Programa parece estar atendendo apenas uma vontade particular de alguns professores de se especializarem em alguma área específica do conhecimento, ainda que fora de sua área de atuação na rede pública. 
É importante observar que, dos 861 professores matriculados em cursos e sua área de atuação, nem todos concluíram o curso - 111 professores desistiram antes de se graduar. Logo, dos 1.225 participantes do Parfor em nossa amostra, apenas $750(61 \%)$ se graduaram em um curso dentro de sua área de atuação e, assim, contribuíram para o alcance da Meta 15 do PNE (BRASIL, 2014). É fundamental, portanto, melhorar os mecanismos de seleção e de validação das inscrições no âmbito do programa pelas secretarias de educação, de forma a assegurar que os professores se matriculem em cursos de graduação nas áreas em que lecionam, atingindo, assim, o objetivo do programa.

Alguns casos, evidentemente, podem gerar dúvidas. Há professores que atuam nos anos iniciais e que se matricularam, por exemplo, no curso de "Letras Inglês". Nesse caso, não é tão simples determinar se o professor está matriculado dentro ou fora de sua área de atuação. Trata-se de uma dificuldade que pode, inclusive, dificultar o processo de validação pelas secretarias. Uma solução seria a criação e a divulgação para as secretarias de uma matriz de correlação entre a(s) disciplina(s) que o professor ministra e os cursos que ele pode pleitear no âmbito do Parfor. Essa matriz, aliada a um sistema de validação cruzada, em que a secretaria informasse as disciplinas ministradas pelo professor e o professor (e/ou a IES) informasse o curso em que ele pretende cursar, permitiriam que um sistema verificasse automaticamente a coerência entre a área de atuação do professor e o curso pretendido no Parfor.

\section{Lição $n^{\circ}$ 2: É necessário repensar a situação dos professores com contrato temporário}

Outra questão relevante é a participação dos professores com contrato temporário no Parfor. Do total de professores que responderam nossa pesquisa, 32\% (391 professores) afirmaram ter um contrato temporário com a rede pública de ensino.

Ao contrário do que aponta Marques (2016), não encontramos fortes indícios de que o tipo de vínculo está correlacionado com a desistência do programa. Como se nota no Painel E da Tabela A.1, entre os desistentes, 34\% apresentavam vínculo temporário com a rede; já entre os formados, 32\% eram temporários.

Acreditamos, contudo, que as razões para se repensar a participação desses professores no Parfor não estão relacionadas à probabilidade de desistência, mas ao vínculo precário que esses profissionais possuem com a rede pública de ensino. O tempo médio de conclusão de uma licenciatura pelo Parfor 
entre os respondentes formados foi de 3,3 anos, sendo que a grande maioria dos professores com contrato temporário estavam vinculados à rede pública há menos de 5 anos.

O cenário é ainda mais preocupante se considerarmos que, dos 391 professores com contrato temporário beneficiados pelo Parfor, 120 (31\%) estavam matriculados em cursos fora de sua área de atuação. Desses, 84 (22\%) já tinham uma graduação. Ou seja, o programa financiou, com recursos públicos, uma $2^{a}$ graduação a professores com vínculo temporário e fora da sua área de atuação.

Outra forma de ver a questão é analisar os professores, em nossa amostra, que atendem simultaneamente a três condições: i) são professores efetivos; ii) matricularam-se em um curso em sua área de atuação; e iii) concluíram o curso e se graduaram pelo Parfor. Somente 514 dos 1.225 professores (42\%) cumprem esses 3 requisitos.

Melhorar a qualidade da formação de professores da educação básica não é um objetivo per se. É um instrumento de melhora da qualidade da educação pública. $\mathrm{O}$ vínculo precário desses profissionais com a rede pública e o longo período necessário para que concluam sua formação no âmbito do Parfor, naturalmente, diminuem a probabilidade de que os estudantes da rede pública sejam beneficiados pela melhora na formação desses professores.

Não se pode ignorar, contudo, que os professores com vínculo temporário constituem uma força de trabalho relevante, principalmente em pequenos municípios e em redes menos estruturadas. Uma alternativa, nesse caso, seria limitar aos professores com vínculo temporário cursos de formação pedagógica ou outros cursos de curta duração, de forma que o período de conclusão da formação ofertada seja mais compatível com o caráter temporário do vínculo desses profissionais com a administração pública.

\section{Lição $\mathrm{n}^{\circ}$ 3: Os principais desafios dos professores-discentes para participação no Parfor estão relacionados à conciliação das tarefas docentes com a carga de estudos e as dificuldades de transporte}

Indagamos os professores a respeito das principais dificuldades que encontraram ao frequentar as aulas do programa. Os docentes podiam apontar mais de uma dificuldade. Como observamos na Tabela 6, para mais de 40\% dos professores, conciliar as tarefas docentes com a carga de estudos do programa foi a principal dificuldade, seguido por dificuldades de transporte (33\%), período das 
aulas $(33 \%)$ e a liberação pela escola $(18 \%)^{7}$. Os resultados da pesquisa vão, assim, ao encontro da conclusão de outros pesquisadores que, conforme vimos na seção 4, apontaram a dificuldade de conciliação das atividades e de liberação para as aulas como dois dos principais desafios do Parfor (JARA, 2014; SOTERO, 2016; MARQUES, 2016)

\section{Tabela 6 - Principais dificuldades encontradas para frequentar as aulas do Parfor}

\begin{tabular}{lcc}
\hline \hline Prin cipais Dificuldades & Desistentes & Formados \\
\hline Conciliar as tarefas docentes com a carga de estudos do & $43 \%$ & $42 \%$ \\
programa & $37 \%$ & $33 \%$ \\
Transporte até o local da aula & $34 \%$ & $33 \%$ \\
Período das aulas & $14 \%$ & $19 \%$ \\
Liberação pela escola para frequentar as aulas & $22 \%$ & $15 \%$ \\
Turno das aulas & $9 \%$ & $17 \%$ \\
Não houve dificuldades & $7 \%$ & $2 \%$ \\
Outro: & \\
\hline
\end{tabular}

Fonte: Elaboração própria a partir dos dados coletados

Os professores desistentes foram questionados, ainda, sobre as principais razões que os levaram a abandonar as aulas do programa (Tabela 7). Também nesse caso, os docentes podiam apontar mais de uma razão. As principais razões apresentadas para desistência dos cursos do Parfor foram: i) a distância entre o município de moradia e onde as aulas eram ministradas (28\%), ii) o período das aulas (dias úteis, férias ou fins de semana) (20\%), iii) o fato do curso não ter atingido as expectativas $(16 \%)$ e iv) a dificuldade de transporte $(16 \%)$. Na categoria "outros", encontram-se os mais diversos motivos: problemas de saúde, dificuldades de relacionamento com professores que ministravam o curso, dificuldades financeiras, ingresso em outro curso na mesma universidade, entre outros.

\footnotetext{
7 O período das aulas (dias úteis, férias e/ou fins de semana) e a liberação pela escola também refletem, nesses casos de forma específica, a dificuldade de conciliação entre atividades.
} 


\section{Tabela 7 - Principais razões para a desistência}

\begin{tabular}{lc}
\hline \hline Princip ais Razões para a Desistência & \\
Distância entre município de moradia e o local das aulas & $28 \%$ \\
Período das aulas & $20 \%$ \\
Dificuldade de Transporte & $16 \%$ \\
O curso não atingiu as expectativas & $16 \%$ \\
Turno das Aulas & $12 \%$ \\
Falta de Liberação da Escola & $11 \%$ \\
Desligam ento da rede pública & $6 \%$ \\
Mudou-se de município & $5 \%$ \\
Outros & $34 \%$ \\
\hline
\end{tabular}

Fonte: Elaboração própria a partir dos dados coletados

A respeito da desistência, interessante ainda notar que não encontramos, na Tabela A.1 do Apêndice, grandes diferenças entre professores desistentes e formados com relação a i) se a aula era no município de residência (Painel M) e ii) a distância média entre o município de residência e o local das aulas (Painel N). Encontramos, contudo, uma diferença significativa com relação à forma de transporte: um percentual significativamente superior dos professores formados se dirigia para as aulas em veículo próprio quando comparamos com os desistentes, o que reforça a importância de fatores de ordem logística - principalmente relacionados à forma de transporte para as aulas - na desistência.

Os resultados da pesquisa mostram, assim, a importância de o Parfor prever alguma forma de apoio para os professores se dirigirem ao local das aulas. Como podemos observar no Painel L da Tabela A.1., mais da metade dos professores frequenta cursos fora de sua área de residência. Um em cada três desses professores tem que percorrer distâncias superiores a $100 \mathrm{~km}$ para frequentar as aulas. Nesse sentido, as condições de transporte claramente têm um impacto significativo nas condições de capacitação do professor-discente.

Outro ponto a se considerar é que, atualmente, o custo de entrada e de saída do programa é zero para os professores-discentes. Assim, os professores não pagam nada nem para ingressar no Parfor nem se abandonarem o curso de graduação sem concluí-lo, ainda que o façam por um motivo estritamente pessoal ${ }^{8}$. Cabe notar que é normal em políticas de capacitação de servidores públicos que o beneficiado tenha que devolver os recursos investidos caso o curso não seja concluído. Dessa forma, uma maneira de se tentar reduzir os altos índices

8 A título de exemplo, entre os professores que desistiram do programa, houve razões tão diversas como "A professora de língua portuguesa me reprovou", "o orientador era arrogante" ou, ainda, "decidi fazer outro curso na mesma faculdade". 
de desistência do programa seria aumentar os custos de saída, prevendo que, caso o professor abandone a graduação por motivos não justificados, tenha que pagar algum tipo de taxa.

Outra forma de garantir maior retorno do investimento à sociedade seria também prever o pagamento de multa no caso de o professor optar por sair da rede pública antes de decorrido determinado período. Ou seja, para obter os benefícios do Parfor, o professor teria que se comprometer a ficar um período mínimo de tempo na rede pública de ensino após a conclusão do programa. Trata-se, novamente, de previsão bastante comum em políticas de capacitação de servidores públicos e, atualmente, inexistentes no âmbito do Parfor.

\section{Lição $n^{\circ}$ 4: É necessário buscar maior envolvimento das secretarias de educação.}

O baixo envolvimento das secretarias de educação pode explicar diversas dificuldades que os professores têm encontrado para conciliar suas rotinas. As secretarias de educação municipais e estaduais possuem diversas atribuições no âmbito do Parfor, conforme disposto no art. $5^{\circ}$ da Portaria no 82, de 2017 (BRASIL, 2017a). Entre essas atribuições, destacam-se: i) orientar os docentes de sua rede sobre o processo de pré-inscrição, seleção e matrícula ; ii) acompanhar o desempenho acadêmico e a taxa de evasão dos matriculados de sua rede; iii) garantir a liberação nos dias e horários do curso de formação; e iv) garantir as condições necessárias para que os docentes de sua rede possam frequentar os cursos de formação.

Contudo, sob a ótica dos professores participantes do programa, grande parte das secretarias de educação não estão realizando a maioria dessas atribuições. Quando questionados a respeito das tarefas cumpridas pela sua respectiva secretaria, mais de $30 \%$ dos professores afirmaram que a secretaria não acompanhou nenhum dos critérios acima relacionados (nas palavras de um professor, o cenário foi de "total falta de acompanhamento"). Para cerca de $20 \%$ dos professores, o envolvimento da secretaria se limitou à "orientação sobre os processos de pré-inscrição, seleção e matrícula”. Menos de 10\% dos professores apontaram o cumprimento integral das atribuições pelas secretarias.

Era também responsabilidade das secretarias a validação dos pré-inscritos, observando, inclusive, se a inscrição foi realizada para o curso correspondente à disciplina de atuação do docente. Como vimos na seção 3, também nesse caso há fortes indícios de que algumas secretarias não estão realizando esse trabalho a contento, dado o alto percentual de professores matriculados fora de sua área de atuação (30\%). Interessante notar que há grande variação quando analisamos 
os números por estado. Enquanto em estados como São Paulo, Pernambuco e Amazonas, há um percentual relativamente baixo de professores em cursos fora de sua área de atuação (5\%,14\% e 16\%, respectivamente); em outros, como Tocantins, Roraima e Santa Catarina, o número é bastante elevado (57\%, 48\% e $46 \%$, respectivamente).

Esses dados indicam que, ao comparar as práticas de diferentes estados no processo de seleção e validação das inscrições do Parfor, seria possível para a CAPES detectar melhores práticas e aconselhar as secretarias acerca da melhor forma de monitorar as inscrições de forma a assegurar que os professores estejam se inscrevendo para cursos nas áreas em que lecionam.

\section{Lição $\mathrm{n}^{\mathrm{o}}$ 5: Academicamente, o programa foi bem avaliado, havendo, contudo, espaço para melhorias}

No questionário, incluímos ainda 4 perguntas que visavam avaliar a qualidade acadêmica dos cursos oferecidos no âmbito do Parfor. A Tabela 8 resume os resultados. Como se nota, os professores alcançaram $91 \%$ de avaliações positivas (muito bom/bom) e as disciplinas, $88 \%$.

Além disso, incentivamos os professores a realizar uma autoavaliação sobre sua capacidade de acompanhamento das aulas e a contribuição das aulas para a atividade docente. O objetivo, no primeiro caso, era avaliar se as aulas não estavam com nível de exigência muito alto, dificultando o acompanhamento pelos professores-discentes. No segundo caso, buscamos avaliar se as aulas contribuíam para as atividades do dia a dia do professor de educação básica. Esses dois critérios também foram positivamente avaliados: 90\% concordaram com a frase "consegui acompanhar as aulas e ter aproveitamento (parcial ou total) dos conteúdos ministrados" e $92 \%$ com a frase "o programa contribuiu (muito) para minha atividade docente" .

9 Os termos entre parênteses diferenciam a avaliação "bom" e "muito bom" em cada um dos critérios. 
Tabela 8 - Avaliação da Qualidade Acadêmica do Programa

\begin{tabular}{lcccc}
\hline \hline Qualidade Acadêmica & $\begin{array}{c}\text { Qualidade dos } \\
\text { Professores }\end{array}$ & $\begin{array}{c}\text { Qualidade das } \\
\text { Disciplinas }\end{array}$ & $\begin{array}{c}\text { Acompanhamento } \\
\text { das Aulas }\end{array}$ & $\begin{array}{c}\text { Contribuição para } \\
\text { Atividade Docente }\end{array}$ \\
\hline Muito Bom & 712 & 550 & 533 & 722 \\
Bom & 407 & 525 & 565 & 403 \\
Razoável & 80 & 128 & 104 & 76 \\
Ruim & 8 & 8 & 10 & 10 \\
Muito Ruim & 18 & 14 & 13 & 14 \\
\hline Total & 1225 & 1225 & 1225 & 1225 \\
\hline
\end{tabular}

Fonte: Elaboração própria a partir dos dados coletados

A capacidade de contribuição do Parfor para o dia a dia dos professores da educação básica foi avaliada, ainda, por meio de duas outras perguntas. $\mathrm{Na}$ primeira, solicitamos que os professores apontassem a frase que melhor descreve o conteúdo ministrado durante o Parfor e a relação desse conteúdo com a atividade docente na educação básica. Para 57\% dos professores-discentes, as aulas do programa eram "teóricas e práticas e apresentavam uma relação direta como dia a dia de um professor da educação básica” e para 23\% as aulas eram "predominantemente aplicadas e com bastante relação com o dia a dia". Por outro lado, 19\% dos professores-discentes afirmaram que as aulas eram "predominante teóricas e apresentavam pouca ou nenhuma relação com o dia a dia de um professor da educação básica". Esse índice chegou a quase 40\% quando consideramos somente os professores que desistiram do Parfor.

$\mathrm{Na}$ segunda, perguntamos se o programa alterou a forma como os professores-discentes preparavam e ministravam suas aulas. Para $79 \%$ dos professores, o programa teve bastante influência na sua atuação como docente. Já para $21 \%$, o programa teve pouca ou nenhuma influência na forma como prepara e ministra suas aulas. Também nesse caso, esse último índice foi significativamente superior para os professores desistentes: $58 \%{ }^{10}$.

Em resumo, o programa foi academicamente bem avaliado pelos professores-discentes. Contudo, há espaço para melhorias, especificamente no que tange à aplicabilidade das aulas e a sua relação com o dia a dia de um professor da educação básica.

10 Nesse caso, deve-se considerar que os professores desistentes podem ter abandonado o curso antes mesmo de concluir seu primeiro ano. Esse é o caso de 86 dos 205 professores desistentes em nossa amostra. 


\section{CONCLUSÃO}

Neste trabalho, realizamos uma avaliação qualitativa do Parfor, tendo por base os egressos - desistentes e formados - do programa. A avaliação permitiu deduzirmos algumas lições importantes acerca do Parfor.

Inicialmente, vimos a necessidade de se repensar os critérios de seleção do programa, uma vez que cerca de $30 \%$ dos professores realizaram cursos fora de sua área de atuação. De forma similar, apontamos para a necessidade de se repensar a participação de professores com contrato temporário, que respondem por mais de 30\% das matrículas do Parfor. O vínculo precário desses profissionais com a administração e o longo tempo necessário para a conclusão de uma formação típica em licenciatura do Parfor (mais de 3 anos) diminuem a probabilidade que o investimento público na formação desses profissionais retorne na forma de melhores aulas para os estudantes. Ambos os fatores parecem fragilizar o Parfor como instrumento para se atingir a Meta 15 do PNE (100\% dos professores formados na área de atuação).

Mostramos, ainda, que somente $42 \%$ professores, em nossa amostra, atendem simultaneamente três condições: i) são professores efetivos; ii) matricularam-se em um curso em sua área de atuação; e iii) concluíram o curso e se graduaram pelo Parfor - reforçando, assim, a necessidade de redesenho do processo de seleção do programa.

Nossa pesquisa permitiu-nos ainda confirmar duas hipóteses comuns na literatura sobre o Parfor: que as principais razões para a desistência estão relacionadas a condições de transporte e a distância para o local das aulas e que uma das principais dificuldades dos professores-discentes é conciliar as aulas do Programa com sua atuação como docente na rede pública. Parte dessa dificuldade, ao que tudo indica, ocorre pelo fato das secretarias de educação, que deveriam ser parceiras na implementação do Programa, não estarem executando seu papel a contento: menos de 10\% dos respondentes apontaram o cumprimento integral das atribuições pelas secretarias, enquanto 50\% afirmaram que a secretaria nada fez ou se limitou a apresentar orientações sobre como realizar a matrícula no programa.

Vimos, por fim, que academicamente o programa foi bem avaliado pelos professores, havendo, contudo, espaço para melhoria no tocante à aplicabilidade do conteúdo ministrado em sala de aula.

Com a intenção de poder contribuir para a produção de conhecimento na área de políticas públicas voltadas para a educação, os resultados desta pesquisa poderão ser utilizados como norteadores de ações dos atuais programas governamentais de formação de professores da rede pública. Especificamente no 
que tange ao Parfor, este trabalho indica a importância de: i) criar mecanismos efetivos de validação das inscrições, evitando que recursos públicos sejam investidos fora do objetivo do programa; ii) criar modalidades do programa de curta duração - mais adequada a professores que tenham um vínculo temporário com as redes; iii) melhorar as condições de transporte dos participantes do Programa para as aulas; iv) prever a assinatura de termo de compromisso com incentivos para que o professor não abandone o curso antes da conclusão e com a exigência de que permaneça por um período mínimo vinculado à rede pública de ensino; v) cobrar maior envolvimento das secretarias de educação, principalmente no que tange à liberação dos professores para as aulas e à validação do processo de inscrição; e vi) realizar acompanhamento pedagógico mais próximo dos cursos de forma a assegurar que o conteúdo ministrado tenha relação com a prática docente.

Finalmente, é importante destacar que a metodologia essencialmente descritiva adotada nessa pesquisa não permite estabelecer relações categóricas de causalidade entre a desistência do Programa e as variáveis analisadas. Nesse sentido, seria importante que, no futuro, a presente pesquisa fosse complementada por avaliações de impacto que permitissem confirmar ou não algumas das hipóteses levantadas ao longo desse trabalho.

\section{REFERÊNCIAS}

ANDRÉ, M. E. D. A. A produção acadêmica sobre formação docente: um estudo comparativo das dissertações e teses dos anos 1990 e 2000. Revista Brasileira de Pesquisa sobre Formação de Professores, v. 1, n. 1, p. 41-56, ago./dez. 2009

AVANCINI, Marta. Fracasso de público. Revista Educação, 2011. Disponível em: http:/ / revistaeducacao.uol.com.br/textos/169/fracasso-de-publico-234946-1. asp.Acesso em: 31 mai. 2019

BRASIL. Lei 9.394, de 20 de dezembro de 1996. Estabelece as diretrizes e bases da educação nacional. Brasilia, 1996. Disponível em: <https://www.planalto.gov. br/ccivil_03/Leis/L9394.htm>. Acesso em: 31 out. 2018.

BRASIL. Lei $\mathbf{n}^{\mathbf{0}} \mathbf{1 0 . 1 7 2}$, de 09 de janeiro de 2001. Aprova o Plano Nacional de Educação e dá outras providências. Disponível em <http://portal.mec.gov.br/ arquivos/pdf/L10172.pdf>. Acesso em: 05 jun. 2019. 
BRASIL. O Plano de Desenvolvimento da Educação: Razões, Princípios e Programas. Brasília: MEC, 2007a. Disponível em: <http://www.gestaoescolar. diaadia.pr.gov.br/arquivos/File/pdf/pde.pdf> Acesso em: 06 jun. 2019.

BRASIL. Decreto $\mathrm{n}^{\circ} \mathbf{6 . 0 9 4}$, de 24 de abril de 2007b. Dispõe sobre a implementação do Plano de Metas Compromisso Todos pela Educação. Disponível em: <http://www.planalto.gov.br/ccivil_03/_ato2007-2010/2007/ decreto/d6094.htm> Acesso em: 06 jun. 2019.

BRASIL. Decreto $\mathbf{n}^{\mathbf{0}} \mathbf{6 . 7 5 5}$, de 29 de janeiro de 2009. Dispõe sobre a Política Nacional de Formação de Profissionais da Educação Básica. Brasília, 2009. Disponível em: < http://www.planalto.gov.br/ccivil_03/_Ato2007-2010/2009/ Decreto/D6755.htm>. Acesso em: 25 mai. 2018.

BRASIL. Lei $\mathbf{n}^{\mathbf{0}} \mathbf{1 3 . 0 0 5}$, de 25 de junho de 2014. Aprova o plano nacional de educação e dá outras providências. Disponível em: <http:/ /www.planalto.gov.br/ CCIVIL_03/_Ato2011-2014/2014/Lei/L13005.htm>. Acesso em: 25 mai. 2018.

BRASIL. Decreto $\mathbf{n}^{\circ}$ 8.752, de 9 de maio de 2016. Dispõe sobre a Política Nacional de Formação de Profissionais da Educação Básica. Brasília, 2016. Disponível em: < http://www.planalto.gov.br/ccivil_03/_Ato2015-2018/2016/ Decreto/D8752.htm\#art19>. Acesso em: 25 mai. 2018.

BRASIL. Portaria n ${ }^{\mathbf{0}}$ 82, de 15 de agosto de 2017. Brasília, 2017a. Disponível em: < https://www.in.gov.br/materia/-/asset_publisher/Kujrw0TZC2Mb/content/ id/20173502/do1-2017-04-20-portaria-n-82-de-17-de-abril-de-2017-20173369>. Acesso em: 25 mai. 2018.

BRASIL. Portaria no 159, de 15 de agosto de 2017. Brasília, 2017b. Disponível em: < https://www.in.gov.br/materia/-/asset_publisher/Kujrw0TZC2Mb/ content/id/19240629/do1-2017-08-17-portaria-n-159-de-15-de-agostode-2017-19240615>. Acesso em: 25 mai. 2018.

CAPES. Plano Nacional de Formação de Professores da Educação Básica - Parfor Presencial - Manual Operativo. 2014. Disponível em: https://www. CAPES.gov.br/images/stories/download/legislacao/2782014-MANUALOPERATIVO-PARFOR.pdf . Acesso em: 10 jun. 2019. 
CUNHA, T. M. M. C. Fortalecimento das políticas de valorização docente: diagnóstico de avaliação curricular de cursos presenciais de $2^{\mathrm{a}}$ licenciatura que estão sendo oferecidos pela Universidade Federal de Pernambuco para o Plano Nacional de Formação de Professores da Educação Básica do estado de Pernambuco; relatório. Brasília: CAPES, UNESCO, 2010. (Documento interno).

D’ÁVILA, Jorge Luis. O Plano Nacional de Formação de Professores da Educação Básica (PARFOR) no Estado de Mato Grosso do Sul: produto de desenvolvimento do estado. 136 f. Tese (Doutorado em Educação) Universidade Federal de Mato Grosso do Sul, Campo Grande, Mato Grosso do Sul. 2014.

GATTI, Bernadete A. Formação Inicial de Professores para a Educação Básica: Pesquisas e Políticas Educacionais. Estudos em Avaliação Educacional, São Paulo, v. 25, n. 57, p. 24-54, jan./abr. 2014.

GATTI, Bernadete A.; BARRETO, Elba de Sá. Professores do Brasil: impasses e desafios. Brasília: UNESCO, 2009.

GATTI, Bernadete A.; BARRETO, Elba de Sá. ANDRÉ, Marli Eliza Dalmazo de Afonso. Políticas docentes no Brasil: um estado da arte. Brasília, DF: UNESCO, 300p. 2011.

INEP. Nota Técnica $\mathbf{n}^{\circ} \mathbf{0 2 0} / 2014$. Indicador de adequação da formação do docente da educação básica. 2014. Disponível em: http://download.inep. gov.br/informacoes_estatisticas/indicadores_educacionais/2014/docente_ formacao_legal/nota_tecnica_indicador_docente_formacao_legal.pdf . Acesso em: 20 de agosto de 2019.

JARA, Iaci da Costa. Sobrecarga dos trabalhadores da educação através do PARFOR/UFMA. In: XII Jornada do HISTEDBR e X Seminário de Dezembro: A crise do capitalismo e seus impactos na educação pública brasileira. São Luís. Anais eletrônicos. 2014. 
MARQUES, Marlucy Pereira. Acesso e permanência dos professores da rede estadual do Amazonas no Plano Nacional de Formação de Professores da Educação Básica (PARFOR). 156 f. Dissertação (Mestrado Profissional em Gestão e Avaliação da Educação Pública) - Faculdade de Educação, Universidade Federal de Juiz de Fora, Juiz de Fora, Minas Gerais. 2016

\section{MAZZEU, Lidiane Teixeira Brasil. A POLÍTICA DE FORMAÇÃo}

DOCENTE NO BRASIL: fundamentos teóricos e epistemológicos. $32^{\mathrm{a}}$ Reunião Anual da Anped: Sociedade, Cultura e Educação: novas regulações? Caxambu, de 04 a 07 de out. 2009.

NEIVA, Luciana Franco de Oliveira. Os processos identitários e de formação de saberes na Política Nacional de Formação de Professores da Educação Básica do IFPI - Floriano. Form@re. Revista do Plano Nacional de Formação de Professores da Educação Básica. Universidade Federal do Piauí, Teresina, v. 2, n. 2, p. 74-91, jul. / dez. 2014.

OLIVEIRA, Jorge Barbosa de. O curso de Pedagogia no Plano Nacional de Professores da Educação Básica (Parfor) no município de São Paulo de Olivença (AM). Dissertação do Mestrado Profissional em Gestão e Avaliação da Educação Pública, Faculdade de Educação, Universidade Federal de Juiz de Fora. Juiz e Fora, 2015.

PAIVA, Francisco da Silva. Avaliação da Implementação do Plano Nacional de Formação de Professores da Educação Básica (PARFOR): Instituto Federal de Educação, Ciência e Tecnologia do Maranhão (IFMA), Campus Codó, período 2010-2016. 101 f. Dissertação (Mestrado em Políticas Públicas) Universidade Federal do Piauí, Teresina, Piauí. 2018.

SHIROMA, Eneida O.; MORAES, Maria Célia M.; EVANGELISTA, Olinda. Política Educacional. $3^{\mathrm{a}}$ ed. Rio de Janeiro: DP\&A, 2004.

SILVA JÚNIOR, C. A. Fortalecimento das políticas de valorização docente: proposição de novos formatos para cursos de licenciatura para o estado da Bahia; relatório. Brasília: CAPES, UNESCO, 2010. (Documento interno). 
SOTERO, Naiara de Araújo. Plano Nacional de Formação de Professores da Educação Básica (PARFOR): as contradições da profissionalização em tempos de pauperização e precarização do trabalho docente. $113 \mathrm{f}$. Dissertação (Mestrado em Educação Brasileira) - Universidade Federal do Ceará, Fortaleza, Ceará. 2016.

YIN, Robert K. Estudo de caso: planejamento e métodos. $2^{\mathrm{a}}$ ed. Porto Alegre: Bookman, 2001.

\section{APÊNDICE}

\begin{tabular}{|c|c|c|c|}
\hline & $\begin{array}{c}\text { Desistentes } \\
205 \\
\text { (1) }\end{array}$ & $\begin{array}{c}\text { Formados } \\
1020 \\
(2)\end{array}$ & $\begin{array}{c}\text { Total } \\
1,225 \\
(3)\end{array}$ \\
\hline \multicolumn{4}{|l|}{ Painel A: Região } \\
\hline Centro-Oeste & 0,04 & 0,04 & 0,04 \\
\hline Nordeste & 0,32 & 0,34 & 0,34 \\
\hline Norte & 0,23 & 0,31 & 0,30 \\
\hline Sudeste & 0,12 & 0,05 & 0,07 \\
\hline Sul & 0,28 & 0,26 & 0,26 \\
\hline \multicolumn{4}{|l|}{ Painel B: Gênero } \\
\hline Feminino & 0,65 & 0,67 & 0,66 \\
\hline Masculino & 0,34 & 0,33 & 0,33 \\
\hline Outro & 0,01 & 0,00 & 0,01 \\
\hline \multicolumn{4}{|l|}{ Painel C: Idade } \\
\hline Menos que 20 anos & 0,05 & 0,04 & 0,04 \\
\hline Entre 21 e 30 anos & 0,43 & 0,42 & 0,43 \\
\hline Entre 31 e 40 anos & 0,36 & 0,39 & 0,38 \\
\hline Entre 41 e 50 anos & 0,14 & 0,13 & 0,13 \\
\hline Entre 51 e 60 anos & 0,01 & 0,02 & 0,02 \\
\hline Mais de 61 anos & 0,00 & 0,00 & 0,00 \\
\hline \multicolumn{4}{|c|}{ Painel D: Rede de Ensino } \\
\hline Estadual & 0,39 & 0,35 & 0,36 \\
\hline Municipal & 0,59 & 0,64 & 0,63 \\
\hline Outros & 0,02 & 0,01 & 0,01 \\
\hline \multicolumn{4}{|c|}{ Painel E: Tipo de Vínculo com a Rede } \\
\hline Efetivo & 0,66 & 0,68 & 0,68 \\
\hline Temporário & 0,34 & 0,32 & 0,32 \\
\hline
\end{tabular}




\begin{tabular}{|c|c|c|c|}
\hline & $\begin{array}{c}\text { Desistentes } \\
205 \\
\text { (1) }\end{array}$ & $\begin{array}{c}\text { Formados } \\
1020 \\
(2)\end{array}$ & $\begin{array}{c}\text { Total } \\
1,225 \\
(3)\end{array}$ \\
\hline \multicolumn{4}{|l|}{ Painel F: Etapa de Ensino } \\
\hline Creche & 0,06 & 0,02 & 0,02 \\
\hline Ensino Infantil & 0,11 & 0,10 & 0,10 \\
\hline Ensino Fundamental - Anos Iniciais & 0,34 & 0,37 & 0,36 \\
\hline Ensino Fundamental - Anos Finais & 0,25 & 0,30 & 0,29 \\
\hline Ensino Médio & 0,24 & 0,22 & 0,22 \\
\hline \multicolumn{4}{|l|}{ Painel G: Disciplina que ministra } \\
\hline Matemática & 0,06 & 0,10 & 0,09 \\
\hline Português & 0,05 & 0,07 & 0,07 \\
\hline Ciências & 0,04 & 0,05 & 0,05 \\
\hline Ensino Fundamental - Anos Iniciais & 0,28 & 0,29 & 0,29 \\
\hline Educação Infantil & 0,11 & 0,09 & 0,09 \\
\hline Outros & 0,45 & 0,41 & 0,41 \\
\hline \multicolumn{4}{|l|}{ Painel H: Tempo do Vínculo com a Rede } \\
\hline 1 a 5 anos & 0,44 & 0,36 & 0,38 \\
\hline 6 a 10 anos & 0,27 & 0,30 & 0,30 \\
\hline 11 anos ou mais & 0,29 & 0,33 & 0,32 \\
\hline \multicolumn{4}{|l|}{ Painel I: Renda } \\
\hline Até $\mathrm{R} \$ 1.000,00$ & 0,21 & 0,19 & 0,19 \\
\hline $\mathrm{R} \$ 1.000,01-\mathrm{R} \$ 2.000,00$ & 0,35 & 0,42 & 0,40 \\
\hline $\mathrm{R} \$ 2.000,01-\mathrm{R} \$ 3.000,00$ & 0,29 & 0,25 & 0,26 \\
\hline $\mathrm{R} \$ 3.000,01-\mathrm{R} \$ 4.000,00$ & 0,10 & 0,09 & 0,09 \\
\hline $\mathrm{R} \$ 4.000,01-\mathrm{R} \$ 5.000,00$ & 0,03 & 0,03 & 0,03 \\
\hline Mais de $\mathrm{R} \$ 5.000,01$ & 0,01 & 0,02 & 0,02 \\
\hline \multicolumn{4}{|l|}{ Painel J: Curso no Parfor } \\
\hline Pedagogia & 0,25 & 0,24 & 0,24 \\
\hline Matemática & 0,08 & 0,08 & 0,08 \\
\hline Educação Física & 0,06 & 0,07 & 0,07 \\
\hline Formação Pedagógica & 0,09 & 0,07 & 0,07 \\
\hline Artes $^{* *}$ & 0,06 & 0,06 & 0,06 \\
\hline Ciências da Computação/Informática & 0,04 & 0,06 & 0,06 \\
\hline Letras - Português & 0,07 & 0,06 & 0,06 \\
\hline Ciências Biológicas/Biologia & 0,03 & 0,05 & 0,05 \\
\hline Letras - Inglês & 0,04 & 0,05 & 0,05 \\
\hline Física & 0,05 & 0,04 & 0,04 \\
\hline Outros & 0,22 & 0,23 & 0,23 \\
\hline
\end{tabular}




\begin{tabular}{|c|c|c|c|}
\hline & $\begin{array}{c}\text { Desistentes } \\
205 \\
(1)\end{array}$ & $\begin{array}{c}\text { Formados } \\
1020 \\
(2)\end{array}$ & $\begin{array}{c}\text { Total } \\
1,225 \\
(3)\end{array}$ \\
\hline \multicolumn{4}{|l|}{ Painel K: Modalidade no Parfor } \\
\hline $1^{\text {a }}$ Licenciatura & 0,34 & 0,40 & 0,39 \\
\hline $2^{\mathrm{a}}$ licenciatura & 0,57 & 0,52 & 0,53 \\
\hline Formação Pedagógica & 0,09 & 0,08 & 0,08 \\
\hline \multicolumn{4}{|l|}{ Painel L: Período das Aulas } \\
\hline Dias úteis & 0,25 & 0,13 & 0,15 \\
\hline Dias úteis e Fins de Semana & 0,06 & 0,10 & 0,09 \\
\hline Férias & 0,25 & 0,30 & 0,29 \\
\hline Fins de Semana & 0,30 & 0,21 & 0,23 \\
\hline Fins de Semana e Férias & 0,07 & 0,18 & 0,16 \\
\hline Outros & 0,06 & 0,08 & 0,08 \\
\hline \multicolumn{4}{|l|}{ Painel M: Turno das Aulas } \\
\hline Matutino & 0,13 & 0,05 & 0,06 \\
\hline Matutino e Vespertino & 0,46 & 0,60 & 0,58 \\
\hline Matutino, Vespertino e Noturno & 0,16 & 0,21 & 0,20 \\
\hline Noturno & 0,16 & 0,08 & 0,09 \\
\hline Outros & 0,09 & 0,06 & 0,07 \\
\hline \multicolumn{4}{|c|}{ Painel N: Aulas no Municipio de Residência } \\
\hline Sim & 0,46 & 0,42 & 0,43 \\
\hline Não & 0,54 & 0,58 & 0,57 \\
\hline \multicolumn{4}{|l|}{ Painel O: Distância média* } \\
\hline até $50 \mathrm{~km}$ & 0,30 & 0,33 & 0,33 \\
\hline $51 \mathrm{~km}$ a $100 \mathrm{~km}$ & 0,35 & 0,31 & 0,32 \\
\hline $101 \mathrm{~km}$ a $150 \mathrm{~km}$ & 0,11 & 0,16 & 0,15 \\
\hline $151 \mathrm{~km}$ a $200 \mathrm{~km}$ & 0,11 & 0,08 & 0,08 \\
\hline mais de $201 \mathrm{~km}$ & 0,13 & 0,11 & 0,11 \\
\hline \multicolumn{4}{|l|}{ Painel P: Forma de Deslocamento } \\
\hline Ônibus & 0,54 & 0,45 & 0,46 \\
\hline Carro próprio & 0,18 & 0,28 & 0,26 \\
\hline Transporte fornecido pela Secretaria & 0,11 & 0,12 & 0,11 \\
\hline Outros*** & 0,17 & 0,16 & 0,16 \\
\hline \multicolumn{4}{|l|}{ Painel Q: Forma de Deslocamento } \\
\hline Ônibus & 0,54 & 0,45 & 0,46 \\
\hline Carro próprio & 0,18 & 0,28 & 0,26 \\
\hline Transporte fornecido pela Secretaria & 0,11 & 0,12 & 0,11 \\
\hline Outros ${ }^{* * *}$ & 0,17 & 0,16 & 0,16 \\
\hline
\end{tabular}




\begin{tabular}{|l|c|c|c|}
\hline & $\begin{array}{c}\text { Desistentes } \\
\mathbf{2 0 5} \\
\mathbf{( 1 )}\end{array}$ & $\begin{array}{c}\text { Formados } \\
\mathbf{1 0 2 0} \\
\mathbf{( 2 )}\end{array}$ & $\begin{array}{c}\text { Total } \\
\mathbf{1 , 2 2 5} \\
\mathbf{( 3 )}\end{array}$ \\
\hline Painel R: Ano de Desistência/Conclusão & & & \\
\hline 2009 & 0,06 & 0,00 & - \\
\hline 2010 & 0,05 & 0,01 & - \\
\hline 2011 & 0,12 & 0,01 & - \\
\hline 2012 & 0,14 & 0,04 & - \\
\hline 2013 & 0,15 & 0,11 & - \\
\hline 2014 & 0,20 & 0,24 & - \\
\hline 2015 & 0,15 & 0,17 & \\
\hline 2016 & 0,07 & 0,18 & \\
\hline 2017 & 0,06 & 0,17 & \\
\hline 2018 & 0,01 & 0,07 & \\
\hline
\end{tabular}

Fonte: Plataforma Freire/CAPES/MEC (dezembro de 2018) e dados coletados pel a pesquisa. Elaboração própria.

Notas: *Sob a denominação "artes", incluimos os cursos de Educação Artistica, Teatro, Dança, Música, Artes Plásticas, entre outros. ** Esta pergunta foi feita somente para professores cujas aulas foram ministradas fora de seu municipio de residência (700 professores). *** Em "outros" estão incluidos professores que declararam se dirigir ao local das aulas em carros alugados, caronas, motos, vans, trens, barcos e "a pé".

\section{Sofia de Brito Ferreira}

Mestre em Administração Pública pelo IDP e Graduada em Pedagogia pela Universidade de Brasília (UnB). Analista de Ciência e Tecnologia da Coordenação de Aperfeiçoamento de Pessoal de Nível Superior (Capes) e Professora da Secretaria de Educação do Distrito Federal. E-mail: sofiabferreira@gmail.com

\section{Caio Cordeiro de Resende}

Doutor (2018) e Mestre (2012) em Economia pela Universidade de Brasília. Atualmente, é Consultor Legislativo no Senado Federal e Coordenador do Mestrado Profissional em Administração Pública - Políticas Públicas e Gestão Governamental do IDP. E-mail: caio.resende@idp.edu.br 